\title{
CONTRADIÇÕES TERRITORIAIS: signos do modelo aplicado na Amazônia
}

Neli Ap. de Mello*

Resumo: O presente artigo objetiva a análise dos resultados territoriais das políticas de meio ambiente e desenvolvimento e dos diferentes modos de organização do espaço na Amazônia brasileira a partir dos anos 1970. As configurações territoriais das políticas públicas são o primeiro vetor desse processo. Indicadores quantitativos e qualitativos enfatizam as disparidades entre a Amazônia conservada e a produtiva. A relação entre programas ambientais, de infra-estrutura e os sistemas produtivos é destacada pela apreciação do investimento governamental e privado, do crescimento de áreas de proteção ambiental, da implantação dos novos "corredores ecológicos".

Palavras-chave: contradições territoriais, políticas públicas, Amazônia brasileira.

Analisar os resultados territoriais das políticas de meio ambiente e desenvolvimento na Amazônia brasileira a partir dos anos 1970 é o objetivo deste artigo. Para isto, selecionamos características regionais ou ambientais que permitissem identificar os diferentes modos de organização do espaço. Com apoio em indicadores quantitativos e qualitativos como o investimento governamental e privado, o crescimento de áreas de proteção ambiental, a implantação dos novos

Doutora em Geografia, pesquisadora associada ao Centro de Desenvolvimento Sustentável da UnB e à UMR IRD/ENS Territoires et Mondialisation dans les Pays du Sud.

Artigos recebidos 15 ago. 2003; aprovado em 22 set. 2003. 
"corredores ecológicos", etc., procuramos destacar a relação entre programas ambientais, programas de infra-estrutura e os sistemas produtivos.

$\mathrm{O}$ aporte metodológico baseia-se em um tripé. $\mathrm{O}$ primeiro suporte se constituiu em uma abordagem cronológico-temática, cuja periodização nos remete à compreensão dos processos anteriores e permite identificar conflitos, convergências, tendências entre as políticas territoriais conservacionistas e de desenvolvimento. Dois vínculos sobressaem entre as políticas territoriais da frente pioneira amazônica e a estruturação do território amazônico; a internacionalização da problemática ambiental sobre o desenvolvimento regional e a incorporação de princípios ambientais e instrumentos institucionais e teóricos da política ambiental. $\mathrm{O}$ segundo, para substantivar a analise teórica e as tendências dos territórios, serviu-se do levantamento de dados e de uma abordagem estatístico-cartográfica. Os indicadores territoriais de proteção (UC e TI) e os de desenvolvimento (investimentos governamentais em infraestrutura nos Eixos Nacionais de Integração e Desenvolvimento ENID - e os fundos constitucionais). O terceiro suporte envolve a compreensão dos discursos das instituições e de determinados segmentos sociais e políticos, mostrando a heterogeneidade de configurações territoriais e as distintas zonas de intervenção.

De fato, as políticas setoriais e as políticas de transferência de desenvolvimento para as regiões ainda periféricas pouco se modificaram e os impactos ambientais (desmatamento, perda de solos, contaminação de cursos d'água, ocupação de áreas de risco, periferias urbanas poluídas, etc.) continuam a ocorrer como antes. Marcas profundas foram deixadas pelas políticas implantadas, a partir dos anos 1970, sobre o território amazônico. As políticas de infra-estrutura continuam a produzir fortes repercussões ambientais e territoriais, apesar da existência de diversos programas de meio ambiente, estruturadores de forma extremamente setorial, mantendo a idéia de que meio ambiente é um setor entre outros, constituídos por atividades específicas de comando e controle, de educação ambiental e de áreas protegidas. 
Novos atores ligados à temática ambiental estão presentes, hoje, na definição de políticas, não somente reivindicando mas, especialmente, definindo novos modelos por meio de experiências locais. Lançam idéias que recolocam localmente as preocupações mundiais sobre o meio ambiente, o desenvolvimento sustentável, proteção de biodiversidade, das florestas, do patrimônio natural, etc. Estes novos discursos ocupam os meios de comunicação em escala nacional e têm importante apelo no seio das políticas públicas.

\section{Por que políticas públicas territoriais na Amazônia?}

O foco central em políticas públicas, num contexto de redução do poder do Estado, faz parte da análise geográfica que explora as diferenças das configurações territoriais nos anos 70 e 90, na qual destacam-se os paradoxos e conflitos. Essas diferenças são caracterizadas pela modificação do foco: se nas décadas de 1970 e 1980 as avaliações retinham a preocupação com os impactos sobre grupos sociais, especialmente indígenas e posseiros, em decorrência do uso de tecnologias e sistemas produtivos inapropriados às florestas, nos anos 90 concentram-se, de um lado, nos impactos socioambientais, e, de outro, na difusão intensa de inúmeras experiências realizadas por diferentes segmentos sociais.

Novos elementos passam a integrar e a intervir no contexto global do país, e, conseqüentemente, da Região. Assim, não é mais possível compreender as tendências territoriais decorrentes de tais políticas sem articulá-las ao processo internacional de transformação e redução do Estado, particularmente intenso em países como o Brasil, e da nova organização da sociedade em redes, sejam elas de solidariedade ou técnicas (Becker, 1996). A estes dois vetores fundamentais agrega-se a existência de novos recortes territoriais como os de Unidades de Conservação públicas e privadas (as Reservas Particulares de Patrimônio Natural), as terras indígenas e as territorialidades manifestadas por novos atores sociais (Andrade, 1996; Almeida, 2000). 
O marco teórico, fundamento da análise, é constituído por diversos fatores: a existência de responsabilidade do Estado no exercício de, pelo menos, dois papéis, o de regulador (Bare, 1997; Deler, 1997) e o de vetor de estruturação e reestruturação do espaço (Becker, 1996; Costa, 1999) impulsionados pelas políticas de desenvolvimento que incorporam valor ao espaço e aumentam frequientemente os impactos sociais e ambientais. Portanto, ainda que a mudança no papel do Estado com a redução do seu poder de influência seja inquestionável, sua presença continua importante. $\mathrm{O}$ planejamento territorial, inexistente desde meados da década de 1980, foi retomado pelo governo federal entre 1995 e 2003 . Este novo planejamento apontou tendências territoriais divergentes e conflitos entre políticas setoriais, registrando, de um lado, infra-estrutura econômica e de outro, o aumento de territórios protegidos.

Assim sendo, os nexos entre políticas públicas e desenvolvimento encerram diversas nuances exigem como requisitos a inter-relação entre atores no planejamento e na gestão, além de requerer, como função de Estado, a gestão ambiental e a redução dos impactos da frente pioneira na Amazônia. A escala local, detentora de um certo poder político, requer também sua maior participação. Também não é possível olvidar que esses vínculos congregam a articulação global-local, derivada da ampliação dos mecanismos de governança global (Maldidier, 1999; Smouts, 2001; Viola \& Leis, 2001).

Outro elemento fundamental para a análise, o conceito de território, é apreendido sob diversos ângulos; engloba aspectos de frentes pioneiras como um espaço em construção, cuja apropriação, estruturação e dinâmicas são específicas de uma sociedade em movimento (Monbeig, 1981; Thery, 1995; Coy, 2001); de apropriação do espaço (Costa, 1996; Santos, 1996; Becker, 1996) e de configurações socioespaciais, essencial na inter-relação da sociedade com seu território (Thery, 1995). Com a mundialização da problemática do meio ambiente, tornou-se imprescindível a inclusão do enfoque ambiental e seus reflexos sobre o território (Guimarães, 1998; Kohlhepp, 1991,1999; Leff, 1998; Ribeiro, 1999; Sachs, 1998). 


\section{A Amazônia “conservada"... das terras indígenas e unidades de conservação}

O sustentáculo territorial da proteção na Amazônia é, sem dúvida, a demarcação das terras indígenas (TI), ao qual se agrega a implantação de Unidades de Conservação (UC). Esses dois tipos de territórios, embora incomparáveis entre si, representam, no entanto, a proteção e a garantia da preservação de um gigantesco patrimônio biológico.

Políticas ambientais conservacionistas somam-se aos territórios indígenas demarcados como mais um elemento importante na manutenção das condições naturais e ecossistêmicas amazônicas. Terras indígenas não são áreas de preservação ambiental, mas como território coletivo indivisível, podem bloquear a fragmentação fundiária e, conseqüentemente, os impactos nocivos do uso da terra. Ambos servem como elementos vitais para a proteção do patrimônio ambiental amazônico sendo, portanto, inscritas no campo das políticas territoriais de proteção.

Mas, as políticas indigenistas nem sempre se pautaram pela diretriz territorial. Somente após a Constituição de 1988 a essencialidade da demarcação foi reconhecida, ainda que esse direito já estivesse inscrito na Constituição de 1934, mostrando aceitar a territorialidade de cada um dos povos indígenas e reconhecendo, juridicamente, suas terras. A delimitação da terra é uma responsabilidade do Estado brasileiro, ${ }^{1}$ exigindo-se o ato governamental de reconhecimento, com a determinação precisa de sua extensão. ${ }^{2}$ Do reconhecimento ao registro são 16 etapas. A efetividade da medida só ocorreu com a complementação de recursos vindos do PPG-7 para o Projeto Terras Indígenas na Amazônia Legal (PPTAL), que tem a FUNAI como executor e que possibilitou a demarcação de 155 terras indígenas entre 1994 e 2001, ${ }^{3}$ a grande maioria na Amazônia ocidental. No final do primeiro semestre de 2003, 170 TI encontravam-se em processo de demarcação. Muitas das terras indígenas são cortadas por obras de infra-estrutura econômica ou situam-se em suas áreas de influência. 
Tabela 1 - Terras e populações indígenas na Amazônia

\begin{tabular}{cccc}
\hline Estados & $\mathbf{N}^{\circ}$ de terras indígenas & População & Área total (ha) \\
Acre & 28 & 7489 & 2141059 \\
Amazonas & 155 & 119409 & 48478907 \\
Amapá & 5 & 4689 & 4196521 \\
Maranhão & 18 & 12648 & 1908387 \\
Mato Grosso & 68 & 19974 & 14646803 \\
Pará & 44 & 42069 & 30807992 \\
Rondônia & 29 & 5135 & 6200854 \\
Roraima & 32 & 31208 & 18022692 \\
Tocantins & 8 & 5996 & 2366052 \\
Amazônia Legal & 387 & 248617 & 128769267 \\
\hline e área total na A.L. & $\mathbf{2 0 , 4 3}$ & $\mathbf{4 1}$ & $\mathbf{5 0 0 6 3 1 6 8 0}$ \\
\hline
\end{tabular}

Fonte: ISA, 2000.

As unidades de conservação representam também um bloqueio à fragmentação territorial e cumprem a função de proteção ambiental, embora possam ter parâmetros e usos diferenciados: em alguns tipos de Unidades de Conservação existem restrições de exploração de recursos florísticos e de presença humana, em outros se permite a exploração econômica, comercialização da madeira ou de outros recursos.

As unidades de conservação, dispersas pelo território, em sua maioria foram localizadas de maneira aleatória e, muitas vezes constituiu-se em objeto de trocas com executores de grandes projetos. Ainda que esta tática possa ser criticada, é importante destacar que a década de 1980 foi a mais promissora para a consolidação do recorte territorial conservacionista, marcada pelo crescimento das unidades de uso direto, especialmente as Reservas Extrativistas (Resex).

Às vésperas da Conferência do Rio, o aumento do número de unidades de conservação era evidente, embora não houvesse processos de regularização fundiária. O caráter político do ato foi significativo: em apenas dois anos - 1989 e 1990 - 29 novas áreas foram estabelecidas sob tutela administrativa do governo federal e, em 1992, nos meses que antecederam a Conferência, duas novas Resex. 


\section{Tabela 2 - Unidades de Conservação nos Estados da Amazônia Legal}

\begin{tabular}{l|c|c}
\hline Estados & $1980 / 1992$ & Total atual \\
\hline Acre & 4 & 9 \\
\hline Amazonas & 24 & 31 \\
\hline Amapá & 6 & 6 \\
\hline Maranhão & 4 & 7 \\
\hline Mato Grosso & 5 & 5 \\
\hline Pará & 4 & 15 \\
\hline Rondônia & 4 & 11 \\
\hline Roraima & 4 & 7 \\
\hline Tocantins & - & 3 \\
\hline Amazônia Legal & $\mathbf{5 7}$ & $\mathbf{8 8}$ \\
\hline
\end{tabular}

Fonte: IBAMA, 2002.

Apesar do crescimento das unidades de conservação, em superfície, as instituições responsáveis por sua gestão debatem-se constantemente com orçamentos reduzidos. Após a Conferência do Rio, esta situação agravou-se com as perdas orçamentárias refletindo na capacidade de manutenção e de gestão das áreas protegidas e promovendo uma redução de US\$ 17 milhões em 4 anos, entre 1989 e 1992, no orçamento do IBAMA. O mesmo ocorreu com os gastos com manejo e manutenção de UC: em 1995, eram R $\$ 29,5$ milhões; foram reduzidos a R \$ 5,3 milhões, em 1999. Dourojeanni \& Pádua (2001) comparam as diferenças de gasto entre 108 países e destacam que o gasto dos países desenvolvidos era em média US \$20,6/ha; este valor decrescia para US\$ 0,27/ha nos países menos desenvolvidos. Nesta classificação, o Brasil, país que mais tinha recebido ajuda externa, teria gastado, em 1996, US\$2,2/ha.

No período de duas décadas, as políticas ambientais se transformaram. Em seu início estiveram fundamentadas no controle ambiental e de proteção de áreas e, no final dos anos 1990, passaram à difusão de instrumentos de ordenamento territorial, bastante conhecidos nas esferas de planejamento. Mas, com um novo potencial, por terem incorporado elementos da dimensão ambiental. A recolocação desse instrumento no seio do debate ecologista como solução ao ordenamento do desenvolvimento, sobretudo o amazônico, foi além de suas próprias capacidades e ainda hoje há imenso imbróglio teórico-metodológico e institucional. A ação pública federal 
tem privilegiado a proteção de territórios à escolha de outros modelos preventivos de ordenamento, investindo em programas que visam o estabelecimento de novas unidades de conservação.

\section{Figura 1 - Áreas protegidas}

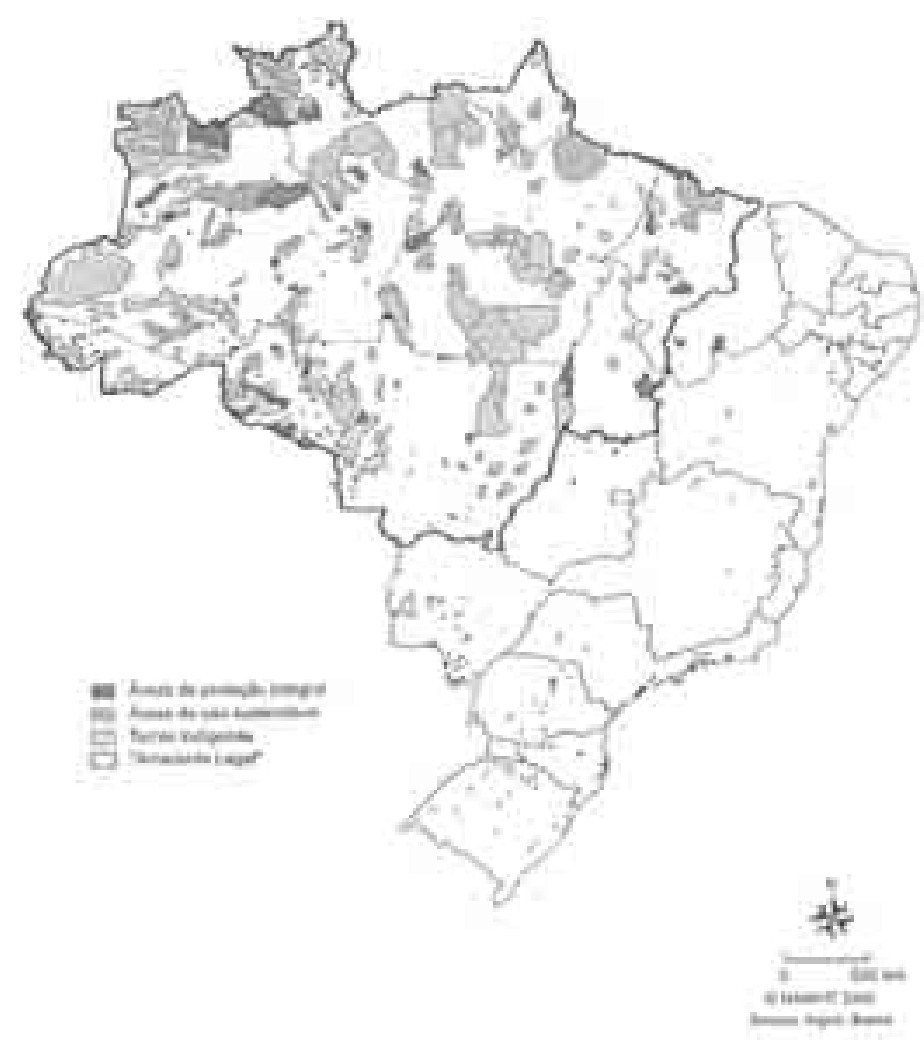

\section{A Amazônia "produtiva"... dos “corredores de exportação"}

A política de desenvolvimento baseia-se em programas governamentais que alicerçam a produção na Região e considerou o orçamento brasileiro de 2000 a $2003^{4}$ (PPA) como indicador do modelo de desenvolvimento definido para o país. A distribuição repete a distorção do crescimento econômico, mostrando uma concentração na região mais dinâmica (32,7\% ao Sudeste), em seguida para a região mais deprimida (24,6\% ao Nordeste). Para as outras regiões foi 
previsto cerca de $21,1 \%$ para o Sul, $12 \%$ para a Região Norte e $9,7 \%$ para o Centro-Oeste.

Analisando o padrão de distribuição espacial dos recursos correspondentes aos 40 programas e 302 ações na Amazônia evidencia-se a concentração nos Eixos Araguaia-Tocantins e no Madeira-Amazonas (Figura 2). Os investimentos programados para os quatro corredores multimodais de transportes montam a US $\$ 3,53$ bilhões, ${ }^{5}$ dos quais aproximadamente $50 \%$ destinados ao Corredor Araguaia Tocantins; $30 \%$ para o Corredor Sudoeste; $15 \%$ para o Corredor Oeste-Norte e 5\% para o Corredor Fronteira Norte.

\section{Figura 2 - Investimentos programados na Amazônia Legal Plano Plurianual (2000-2003)}

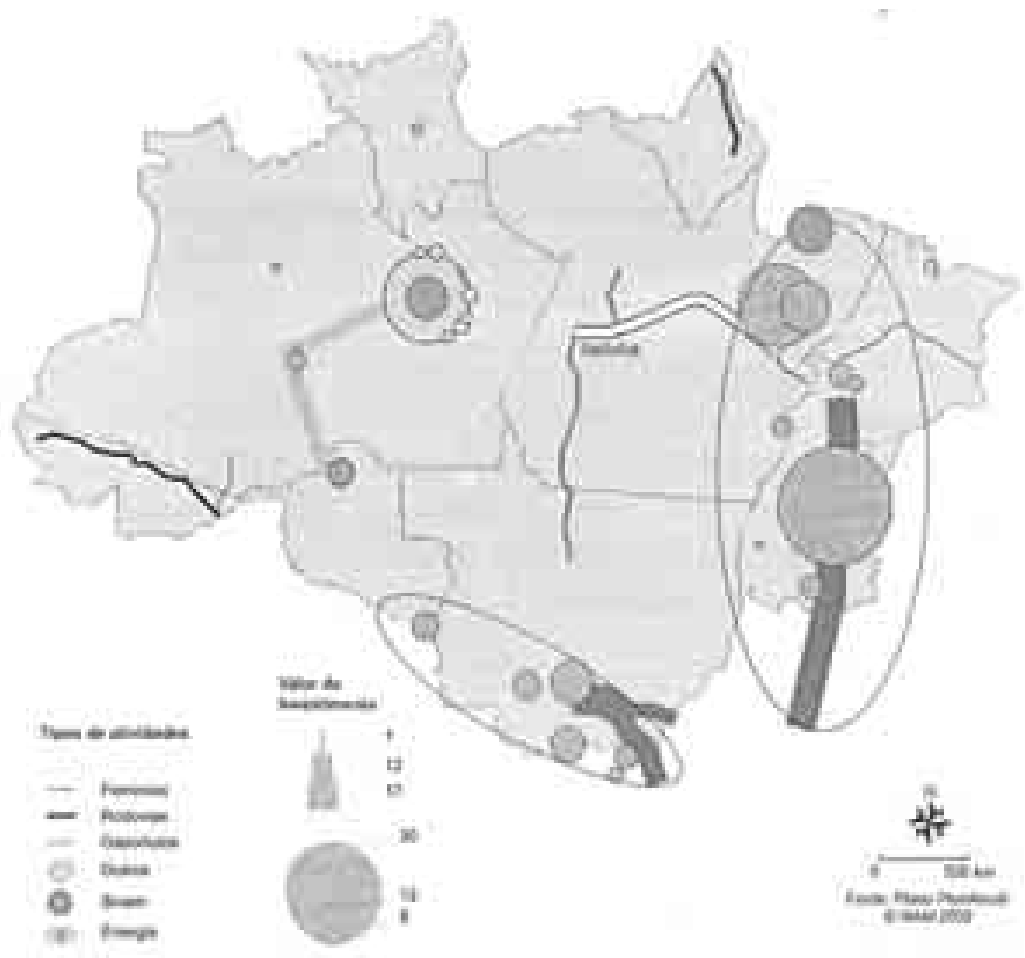


Os Eixos Madeira-Amazonas e Araguaia-Tocantins destacamse como os mais importantes para a Amazônia Legal pela diversidade de ações e volume de investimentos, estando a infra-estrutura viária e energética concentrada no último. Certamente, maiores impactos socioambientais poderão ocorrer nesse Eixo. Além da distribuição ao longo dos Eixos, algumas das capitais regionais destacam-se também pela concentração de recursos e atividades: Manaus, Belém, Porto Velho e Cuiabá; entretanto, a primazia de Manaus é evidente.

A maior diversidade de ações no Eixo Madeira-Amazonas indica que este poderá tornar-se, de fato, um espaço para novas experiências com uso de tecnologias, de informações, de técnicas ambientais socialmente aceitáveis, evitando-se reproduzir o modelo anterior de integração econômica dos Cerrados ao território nacional, com exclusão social e degradação ambiental.

A tendência da incorporação progressiva da Amazônia Ocidental ao mercado nacional e às redes logísticas dos países vizinhos se faz completando e adensando as conexões nacionais e internacionais, inserindo a região no processo de globalização, permitindo movimentação de capitais nacionais e internacionais, constituídos pelo aumento de fluxos de bens e serviços econômicos (Costa, 1999).

O Eixo Araguaia-Tocantins representa, pela concentração de investimentos em setores importantes da infra-estrutura, a verdadeira configuração espacial do futuro desenvolvimento do país: de estruturação central, no sentido norte-sul, resulta de uma visão estratégica do governo federal. Esta articulação e o padrão territorial reforçam, todavia, as condições de competitividade econômica, com exclusão, e aproveita-se das vantagens da rede de fluxos dos ciclos de expansão anteriores, irradiando influências para outros setores.

É o core do modelo de planejamento no contexto dos planos do Governo Fernando Henrique Cardoso, repetindo-se um modelo espacialmente seletivo por articular o desenvolvimento ao longo dos Eixos, (re)equipando-os em função dos novos fluxos econômicos e desprezando as áreas não rentáveis, e, portanto, aumenta a velocidade das transformações nestas áreas selecionadas paralelamente ao aumento da rede de oportunidades aos investidores. 


\section{Mapa 3 - Investimentos Eixo Araguaia-Tocantins}

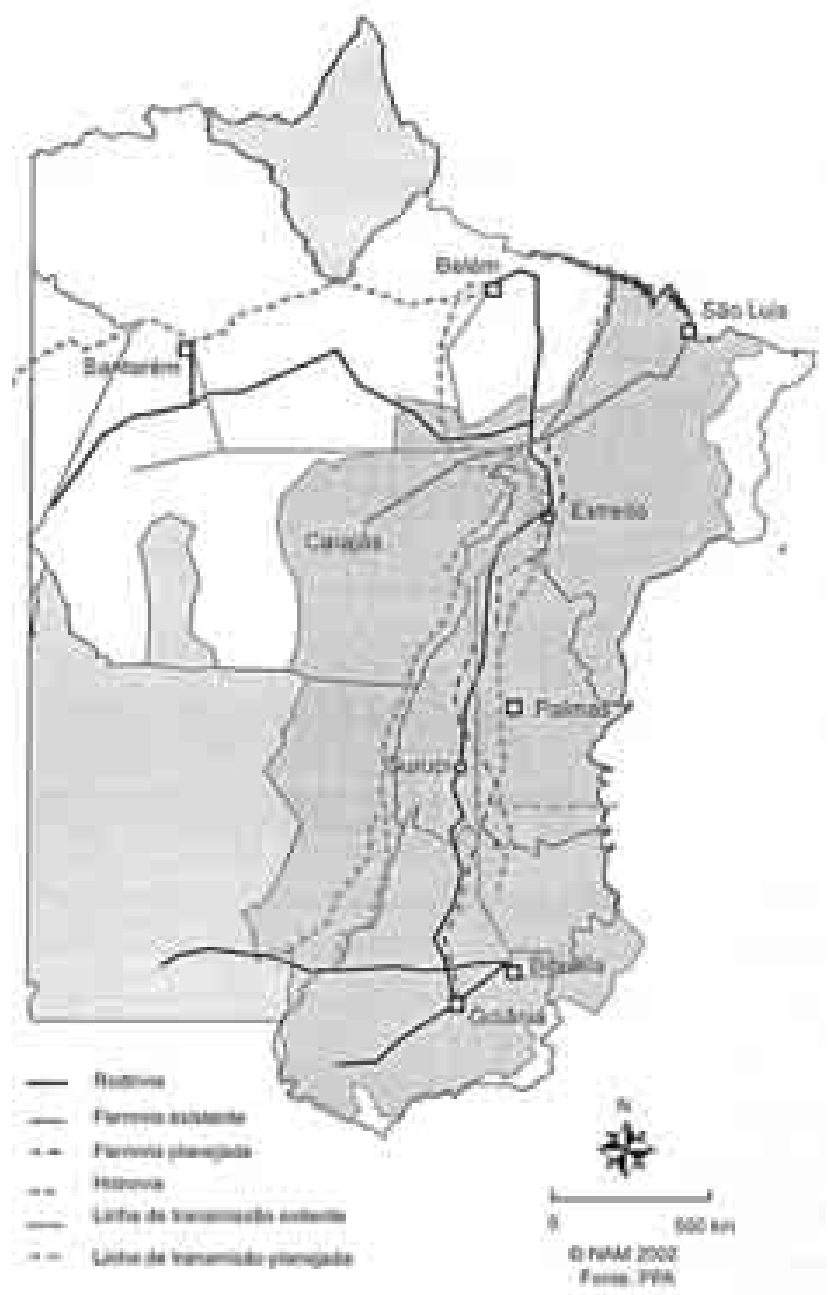

\section{Investimentos ampliam a competitividade da soja}

Os investimentos em infra-estrutura respondem à necessidade de circulação e de exportação do principal produto da pauta comercial brasileira: a soja. Essa produção vem sendo crescente nos Estados da Amazônia Legal. Entre 1991-1994, a produção do Pará, Tocantins, Goiás cresceu $81 \%$, com produtividade superior à média nacional 
(Brasil, MPO, 1997). No ano 2000, o Mato Grosso tornou-se o maior produtor de soja do país, com o maior índice de produtividade.

\section{Tabela 3 - Produção de soja (t) em Estados da Amazônia Legal e no Brasil}

\begin{tabular}{lcccccc}
\hline ANO & MARANHÃO & RONDÔNIA & PARÁ & TOCANTINS & MATO GROSSO & BRASIL \\
1993 & 87.370 & 10.852 & - & 26.506 & 4.118 .726 & 22.590 .978 \\
1994 & 140.637 & 11.052 & - & 57.585 & 5.319 .793 & 24.931 .832 \\
1995 & 162.375 & 10.800 & - & 36.191 & 5.491 .426 & 25.651 .272 \\
1996 & 194.868 & 11.250 & - & 14.030 & 4.759 .114 & 23.210 .877 \\
1997 & 252.000 & 8.900 & 1.180 & 19.700 & 5.721 .300 & 26.160 .000 \\
1998 & 302.400 & 14.100 & & 80.200 & 7.150 .000 & 31.364 .400 \\
1999 & 390.500 & 19.500 & & 93.800 & 7.134 .400 & 30.752 .800 \\
2000 & 454.781 & 36.222 & 2.602 & 144.362 & 8.774 .470 & 32.820 .826 \\
2001 & 491.083 & 68.687 & 2.291 & 188.226 & 9.533 .286 & 37.907 .259 \\
\hline
\end{tabular}

Fonte: IBGE, Produção Agrícola Municipal, de 1990 a 2001.

Um forte processo de concentração fundiária tem ocorrido neste Arco amazônico, formado pelos Estados do Mato Grosso, Pará e Tocantins, por ser a condição necessária para produções que exigem investimento de capital e mecanização. Especialmente no Mato Grosso, nas áreas de influência da BR-163, as propriedades de $10 \mathrm{a}$ 20 mil hectares são predominantes, em lugares que anteriormente foram áreas de projetos de colonização privados, com propriedades de aproximadamente 200 ha.

Paralelamente aos movimentos privados de concentração e expulsão, o governo intensifica, também, os investimentos para viabilizar um sistema mais eficiente para o escoamento da produção e aumentar a competitividade brasileira no mercado mundial, e, ao mesmo tempo, estimula a ocorrência de investimentos privados em agro-indústrias, em função da proximidade das áreas de produção agrícola (soja, milho, algodão) ou pecuária (aves, suínos, bovinos), de madeira ou de produção resultante do desdobramento do complexo de Carajás. O perfil dessa dinâmica de frente pioneira caracterizavase inicialmente, pela substituição da floresta e da pequena produção pela pecuária, tendo sido posteriormente substituída pela produção de exportação. A dinâmica fundiária também se repete desde as antigas frentes pioneiras (São Paulo, norte do Paraná, etc.), posteriormente 
na Amazônia (Rondônia, Mato Grosso, Transamazônia), e as tendências de que se repita nas áreas de influência dos Eixos são reforçadas ao se incorporarem novas terras aos processos produtivos.

Os dados levantados pelo setor interessado, no estado do Mato Grosso, apresentam algumas divergências com as informações do IBGE, mas mostram a importância da variação de área e de tonelagem.

\section{Tabela 4 - Evolução da área e produção de soja no Estado do Mato Grosso}

\begin{tabular}{|c|c|c|c|}
\hline SAFRA & ÁREA (ha) & PRODUÇÃO (ton) & VARIAÇÃO AREA \% \\
\hline $92 / 93$ & 1.678 .532 & 4.118 .726 & 15,47 \\
\hline $93 / 94$ & 2.022 .956 & 5.319 .793 & 20,52 \\
\hline $94 / 95$ & 2.322 .825 & 5.491 .426 & 14,82 \\
\hline $95 / 96$ & 1.905 .200 & 4.686 .800 & $(17.98)$ \\
\hline $96 / 97$ & 2.095 .700 & 5.721 .300 & 10.00 \\
\hline $97 / 98$ & 2.649 .530 & 7.159 .751 & 26,43 \\
\hline $98 / 99$ & 2.548 .000 & 7.134 .400 & -2 \\
\hline $99 / 00$ & 2.637 .200 & 7.647 .900 & 3,5 \\
\hline
\end{tabular}

Fonte: Federação de Agricultura do Estado do Mato Grosso, 2002.

Analisado pelo ângulo do empenho governamental, a maioria dos quadros técnicos do governo compartilhava a idéia de responder aos desafios da globalização, da abertura comercial e da inserção competitiva da economia brasileira com uma estratégia organizada em agendas de desenvolvimento. Na prática, mesmo que alguns setores, notadamente o setor ambiental, discordassem da forma de abordagem do tema, a opção pela competitividade brasileira no mercado mundial prevalece. Em 2003, a mesma estratégia permanece... apesar das mudanças de orientação global do novo governo.

\section{O Avança Brasil e os conflitos territoriais}

A Amazônia de hoje continua sendo exposta a contraditórias políticas públicas, origem de diferenciadas repercussões. Mesmo com a grande evolução de leis, mecanismos e instrumentos operacionais, 
as políticas ambientais continuam fechadas em si, sendo poucos os setores a servirem-se desses instrumentos. Por outro lado, as políticas de base econômica repetem antigos modelos. Ao privilegiar a construção das redes logísticas no interior dos Eixos Nacionais de Integração e Desenvolvimento, as estratégias territoriais da política federal provocam inúmeras transformações na Região, redirecionam as dinâmicas no território e influenciam significativamente os impactos ambientais.

A implantação de novas infra-estruturas provoca desmatamentos por incorporarem ao espaço produtivo nacional novas áreas e, ainda que o desmatamento não seja um problema apenas brasileiro, torna-se o ingrediente de agravamento do processo. A vulnerabilidade da floresta, em função das características do novo estrato vegetal reconstituído depois das queimadas e extração seletiva de madeira, continua estimulando discussões em foros mundiais e aumentando o número de proposições de segmentos ambientalistas para contê-las.

\section{Transportes, desmatamento e queimadas}

O vetor infra-estrutura do Avança Brasil é um dos mais impactantes. As primeiras conexões se sobressaem, em especial, entre os locais de agricultura moderna e as grandes extensões plantadas e as atuais taxas de desmatamento. A alteração no perfil dos responsáveis e a concentração no Arco do Desmatamento ${ }^{6}$ foram mencionadas no anúncio das taxas de desmatamento MMA e INPE (1999 e 2000). ${ }^{7}$ A conjunção desses elementos com as condições de inflamabilidade da floresta fazem sobressair zonas de risco potenciais, como alertado por NEPSTAD et al. (2000). Os investimentos apenas nos corredores de transportes desses Eixos também colocam em risco outros 187.000 $\mathrm{km}^{2}$ de florestas frágeis, comprovados como inflamáveis durante a seca de 1997 e 1998.

Várias das rodovias previstas cortam áreas de proteção ambiental e terras indígenas e impactos são também previsíveis: as rodovias BR-421 entre Ariquemes, Guajará-Mirim e Nova Mamoré, e a BR-429 entre Presidente Médici e São Miguel do Guaporé, ambas em Rondônia, atravessando as terras indígenas (Uru-Eu-Wau-Wau e Igarapé Lago), o Parque Nacional de Pacaás Novos, o Parque Estadual 
de Guajará-Mirim, a Resex Rio Ouro Preto, alguns deles ainda não completamente demarcados; o asfaltamento da BR-364 no Acre entre Sena Madureira e Cruzeiro do Sul cruzam novas áreas identificadas nos estudos e propostas de estratégias de conservação da biodiversidade, como Riozinho da Liberdade, Rio Liberdade e Médio Envira, coincidindo, assim com as áreas de alta pressão antrópica indicadas em MMA/SBF (2001).

As estratégias territoriais destas ações promovem gradualmente a incorporação dos territórios do extremo ocidental do país, refazendo, um pouco mais a Oeste, o traçado da Belém-Brasília, com a recuperação da Cuiabá-Santarém, e um novo arco formado pela ligação de Porto Velho-Manaus-Boa Vista. O volume de investimentos poderá gerar o aparecimento de pequenas cidades, revitalizar vilas, incentivar novas migrações, criar novos espaços propícios à produção agrícola comercial.

Em princípio, em regiões de alta densidade hidrográfica, a escolha da hidrovia deveria representar uma alternativa melhor que a rodovia. Mas, hidrovias podem também gerar fortes impactos, pois a perenização da navegação implicará em obras de derrocamento, dragagem e sinalização e devem ser licenciadas pelo setor ambiental. Dentro deste quadro inserem-se os projetos das hidrovias AraguaiaTocantins e Tapajós, cujas obras foram suspensas por ação civil pública do Ministério Público Federal, em vista de não terem sido aceitos os estudos de avaliação de impactos.

Cenários alternativos à hidrovia foram também considerados, mas, o custo da ferrovia é 14 vezes (US\$1,82 bilhões) maior que o da hidrovia. Se a procura de novos parâmetros orientarem, de fato, a escolha do modelo de desenvolvimento e de um dos modos de transportes, o diferencial no volume de desmatamento seria um elemento importante para induzir essa escolha, apesar da significativa diferença de custo de implantação. Os números do desmatamento mostram que enquanto na implantação de uma rodovia haveria um destamamento de 100 milhões de $\mathrm{m}^{2}$ para $2500 \mathrm{~km}$, este valor baixaria para 77,1 milhões de $\mathrm{m}^{2}$ no caso da implantação de uma ferrovia e praticamente inexistente quando o empreendimento trata-se de uma hidrovia. 
Outro vetor de comprometimento e impacto da política de infraestrutura está relacionado aos territórios legalmente protegidos - terras indígenas, unidades de conservação estaduais e federais - e aqueles que deveriam estar protegidos pelo grau de extrema importância para a conservação da biodiversidade existente. Se os investimentos previstos no Avança Brasil forem realizados, será colocado em risco o processo de consolidação das áreas protegidas ao serem afetadas pelos impactos da construção da infra-estrutura viária.

\section{Tabela 5 - Risco de impactos sobre áreas protegidas}

\begin{tabular}{|c|c|c|}
\hline Tipo de área & Numero de áreas afetadas & $\begin{array}{c}\text { \% sobre o total de unidades } \\
\text { na Amazônia }\end{array}$ \\
\hline Terras Indígenas & 31 & 8,4 \\
\hline Unidades de Conservação Federal & 18 & 22,2 \\
\hline $\begin{array}{c}\text { Unidade de Conservação Estadual } \\
\text { Áreas Críticas para Conservação da } \\
\text { Biodiversidade }\end{array}$ & 8 & 10,9 \\
\hline Total & 68 & $17,6^{*}$ \\
\hline
\end{tabular}

Fonte: Nepstad et al (2000).

* Cf. Instituição Sócio-Ambiental e Machado \& Aguiar (2001).

Por isso, em 1999, segmentos sociais e governamentais propuseram estratégias para conservação da biodiversidade, mapeando-se áreas de importante biodiversidade, ${ }^{8}$ constituindo grandes agrupamentos, no sentido Leste-Oeste, que poderiam formar corredores ecológicos, embora ainda não tenham sido inseridos na política de conservação da biodiversidade. Mas, os espaços de produção e as redes logísticas dos Eixos foram estabelecidos no sentido Norte-Sul, formando conexões com portos de exportação.

As diferentes estratégias foram traçadas separadamente, não considerando as consequiências de uma sobre a outra. Estas tendências indicariam que os espaços destinados à conservação e experimentação de modelos sustentáveis estariam destinados a competir com os espaços da produção. Nesta competição, os espaços de preservação se reduzirão a ilhas isoladas, que poderão ser invadidas para a posse de terra ou mesmo para a apropriação dos recursos naturais, como ocorre nas áreas protegidas da Mata Atlântica ou dos Cerrados. As configurações territoriais resultantes desta política estão marcadas 
pela distinção dos diversos espaços, destacando-se inúmeros espaços de conflitos, ao lado de outros de preservação, de consolidação econômica e, ainda, aqueles que estão sendo integrados pelo avanço capitalista.

\section{Considerações finais}

O modelo de desenvolvimento a duas velocidades, identificado no início da década de 90 por Théry (1995) continua se repetindo agora, não apenas separando o espaço-tempo ligado aos rios ou às rodovias, mas transpondo-se para os espaços-tempos da proteção e dos usos impactantes da infra-estrutura econômica. São velocidades de maturação e de implantação diferenciadas.

Para a implantação de infra-estrutura há conhecimento e técnicas, investimentos disponíveis, espaços selecionados. Por outro lado, aos poucos, políticas e ações demonstrativas vem sendo geradas como resultados de programas ambientais. Como são processos extremamente lentos, que cobrem superfícies menores, acabam tornando-se marginais, criando dois modelos de organização espacial: experiências marginais sustentáveis em poucos locais, por vezes integradas aos mercados nacional e local, em muitos casos com recursos, tecnologias e formas de gestão também internacionais, enquanto outras áreas produtoras de soja, sobretudo, são inseridas na competição do mercado mundial.

Assim, sintetizando um balanço das políticas implantadas na Amazônia, a partir dos anos 70, pode-se destacar que as mesmas atingiram seus objetivos de integração territorial e proteção da soberania: ao aumentar a população da Região, ao fazer surgir cidades ao longo das rodovias, ao forçar o aparecimento de uma produção comercial e/ou de exportação resultante da implantação de infraestrutura viária, energética e de comunicações, e, especialmente, ao desmantelar os focos de pressão social existentes no país. Mas, inúmeros problemas ambientais e sociais foram daí resultantes. Produto do longo período de ocupação da Amazônia, os 550.000 $\mathrm{km}^{2}$ já desmatados (INPE, 2000) vêm acelerando o ritmo nos últimos anos, e comprovam a dinâmica predatória das frentes pioneiras, $\mathrm{o}$ garimpo mineral, o corte raso das florestas promove a perda da 
biodiversidade, a queima da vegetação, o assoreamento e contaminação dos rios, a aceleração dos processos erosivos. A estes aspectos, somaram-se questões sociais de expulsão de posseiros e pequenos proprietários, a marginalização de segmentos sociais, a periferização até em pequenas cidades.

As tendências modelizadas para o futuro, com a implantação das obras previstas no Avança Brasil, implicam continuar a incorporar novas áreas e a provocar desperdício de recursos naturais. Repetindose o processo com as mesmas variáveis, é bastante provável que a pressão, tanto sobre novas áreas, ainda pouco alteradas, como em regiões onde as dinâmicas de ocupação do espaço já resultaram em modificações dos ecossistemas amazônicos, seja ainda mais intensiva. A relação custo-benefício é mais vantajosa na incorporação de novas áreas da floresta nativa, pois o custo de derrubada da floresta primária é mais reduzido que o custo de limpeza das áreas de capoeiras ou de áreas que já se encontram alteradas. Isto significa novos desmatamentos. À medida que as estradas, antes intransitáveis, serão melhoradas e novas serão construídas, aumentando-se a malha viária de 6.300 para $11.000 \mathrm{~km}$, elas tornarão acessíveis e valorizadas áreas antes "marginais", fazendo repetir o padrão já conhecido dos últimos 40 anos.

Reforça-se a idéia de que a política ambiental constitui-se antes em discursos, dados que os resultados concretos ainda são poucos. As ações de controle efetivo do uso dos recursos naturais são insuficientes, a promoção de outros modos de utilização dos recursos naturais, especialmente a madeira, ainda não estão assegurados. O que mudou nos últimos anos foi que algumas políticas estaduais formulam diretrizes com novos parâmetros e novos modelos.

No entanto, sabe-se também que é preciso ampliar o universo dos argumentos econômicos que servem de base nas discussões de políticas públicas ambientais, incluindo elementos baseados na prestação de serviços ambientais e no próprio valor da floresta. A concepção mais moderna da floresta implica em vê-la como uma fonte de serviços globais, pois mantê-la em pé pode significar contribuição tanto no nível local, como nacional ou mundial. Assim, é vital a continuidade da ação pública de planejamento e ordenamento do 
território amazônico, na qual predomina a dimensão econômica sobre as atuais exigências de conservação ambiental ou mesmo de desenvolvimento sustentável.

Ao passar-se de uma lógica pioneira de ocupação do espaço com seus eixos de penetração viária e suas frentes de colonização para uma lógica de implantação de redes de circulação, de energia, de comunicações e de investimentos com vínculos ao mercado mundial e à integração continental, numa economia consolidada, o crescimento e o consumo anárquico do espaço amazônico pode resultar das contradições entre as lógicas liberais de desenvolvimento econômico, sob o domínio do jogo de interesses privados, e as lógicas de conservação ou de desenvolvimento sustentável, sob o domínio dos interesses locais e internacionais.

\section{Nota}

1 O Estatuto do Índio (Lei n ${ }^{\circ}$ 6.001/73) atribuiu à FUNAI a iniciativa de orientá-los e executá-los e, encontra-se em revisão pelo Congresso Nacional. Assunto polêmico em função de discordâncias a respeito da tutela jurídica, da integração indígena e da previsão de remoção de grupos por razões de segurança, por exploração mineral, por realização de obras públicas.

2 Até 1996 as diferentes fases da demarcação eram atribuição do Estado e a lentidão do processo foi marcante: as inúmeras fases e procedimentos somavam-se à falta de prioridade durante o período do governo militar. Esse não aceitava o reconhecimento em território contínuo, por isso muitas vezes suas terras foram propostas em diversas unidades, e utilizando-se de argumentos ecológicos para o seu retalhamento.

3 Os recursos contratados são em dólares e gastos em reais. Com a desvalorização da moeda brasileira, o câmbio para reais é em volume crescente porque o valor em dólares é fixo.

4 Cerca US\$ 560 milhões, ao câmbio de 03/01/2000.

5 O valor atribuído no orçamento foi de $\mathrm{R} \$ 6,5$ bilhões, transformado em dólares ao câmbio de $\mathrm{R} \$ 1,84$, na data de 03/01/2000.

6 Denominação freqüente nos meios técnicos ambientalistas, o Arco de Desmatamento é uma larga faixa, em formato de "meia-lua" onde há predomínio dos processos de desmatamento e fogo, englobando parcialmente os Estados de Rondônia, Mato Grosso, Pará e Tocantins. 
7 As duas instituições indicaram alterações metodológicas na obtenção dos dados: a partir daquela data, o monitoramento passou a ser realizado, separadamente, por tipo de vegetação, ou seja, passaram a acompanhar como este processo ocorre em cada ecossistema.

8 O Seminário de Macapá, realizado em outubro de 1999, promovido pelo Programa Nacional de Diversidade Biológica (Pronabio) propôs áreas prioritárias para conservação por meio de 4 categorias (extrema, alta, muita e provável importância). Os estudos básicos foram realizados pelo Instituto de Pesquisa Ambiental da Amazônia e Instituto Sócio-Ambiental dentro do projeto "Cenários futuros para a Amazônia".

Abstract: The present article analyzes the territorial results of the environment and development policies and the territorial organization of the Brazilian Amazon until 1970. The first vector of this process lies in the territorial configurations of the public policies. Quantitative and qualitative indicators emphasize the disparities between protected and productive Amazônia. The relation between environmental programs, the building of infrastructures and productive systems is evaluated by taking into account the governmental and private investments, the growth of protected areas and the implantation of the new "ecological corridors".

Key-words: territorial contradictions, public policies, Brazilian Amazon

Resumé: L'objectif de cet article est l'analyse des résultats territoriaux des politiques d'environnement ou de développement, ainsi que l'organisation de l'espace de l'Amazonie brésilienne à partir des années 1970 . Le premier facteur de ce processus dépend des configurations territoriales des politiques publiques. Des indicateurs quantitatifs et qualitatifs soulignent les disparités entre l'Amazonie protégée et l'Amazonie productive. Il analyse la relation entre les programmes environnementaux, les infrastructures et les systèmes productifs en prenant em compte sucessivement l'évaluation des investissements gouvernementaux et privés, la croissance de zones de protection environnementale et l'implantation des nouveaux "couloirs écologiques".

Mots-clés: contradictions territoriales, politiques publiques, Amazonie brésilienne.

\section{Referências bibliográficas}

ALMEIDA, Alfredo Wagner. Mapas temáticos ou mapas situacionais? A reconceituação dos conflitos sócio-ambientais e os fatores étnicos como delineadores de novos procedimentos técnicos de zoneamento. In: SEMINÁRIO SOBRE O ZEE NA AMAZÔNIA BRASILEIRA, 
2000, Manaus. Anais... Curitiba: CD-card Latinoamérica, 2000. 1 CD.

BARÉ, Jean-François. Le prêt et le résultat: eléments d'une chronique de l'évaluation à la Banque Myondiale. In: BARÉ, J-F. (Org). Regards interdisciplinaires sur les politiques de développement. Paris/ Montréal: L'Harmattan, 1997. p. 49-74.

BECKER, Bertha. Novos rumos da política regional: por um desenvolvimento sustentável da fronteira amazônica. In: BECKER, Bertha; MIRANDA, Mariana (Orgs.). A Geografia Política do desenvolvimento sustentável. Rio de Janeiro: Editora da UFRJ, 1996. p. 421-443.

. Síntese do processo de ocupação da Amazônia: lições do passado e desafios do presente. In: BRASIL. Ministério do Meio Ambiente (Org.). Causas e dinâmica do desmatamento na Amazônia. Brasília: MMA, 2001. p.5-28.

BRASIL. MPO. Secretaria Especial de Políticas Regionais. Bases para um Programa de Desenvolvimento Integrado da Região Centro-Oeste. Brasília: Universa, Universidade Católica de Brasília, 1997.

Ministério do Meio Ambiente. Avaliação e identificação de ações prioritárias para a conservação, utilização sustentável e repartição dos benefícios da biodiversidade na Amazônia brasileira. Brasília: MMA/SBF, 2001.

COSTA, Wanderley M. da. Políticas territoriais brasileiras no contexto da integração sul-americana. Território, Rio de Janeiro, v. 4, n. 7, 1999.

As possibilidades do planejamento ambiental no Brasil. In: BECKER, Bertha; MIRANDA, Mariana (Orgs.). A Geografia Política do desenvolvimento sustentável. Rio de Janeiro: Editora da UFRJ, 1996. p. 445-456.

COY, Martin. Entre a globalização e a regionalização: efeitos da modernização, conflitos de interesse e fatores determinantes do desenvolvimento regional sustentável no espaço rural brasileiro. In KOHLHEPP, Gerd et al. (Org.). Brasil: modernização e globalização. Madrid-Frankfurt am Main: 2001. p. 259-273.

DELER, Jean-Paul. A la recherche des espaces du développement au Pérou: l'échec d'une régionalisation annoncée. In: BARÉ, J-F. (Org). Regards interdisciplinaires sur les politiques de développement. Paris/ Montréal: L'Harmattan, 1997. p. 75-100.

FEDERAÇÃO DE AGRICULTURA DO ESTADO DO MATO GROSSO. Entrevista com Amado de Oliveira Filho. 07 jul. 2002.

GUIMARÃES, Roberto. Modernidade, Meio Ambiente e Ética: um novo paradigma de desenvolvimento. In: CONFERÊNCIA INTERNACIONAL AMAZONIA 21: UMA AGENDA PARA UM MUNDO SUSTENTÁVEL. 1998, Brasília. Anais... Brasília: DMF Congressos, 1998.

IBGE. www.ibge.gov.br/sidra/produçãoagricolamunicipal. 1990 a 2001 . 
IBAMA. http://www2.ibama.gov.br/unidades/geralucs/tabl.htm\#topo.

INSTITUTO SÓCIO-AMBIENTAL. www.socioambiental.org.

INPE/MCT. Monitoramento da floresta amazônica brasileira por satélite (1998/1999).

INPE/MMA. Monitoramento da floresta amazônica brasileira por satélite (1999/2000).

KOHLHEPP, Gerd. Grandes projetos de barragem no Brasil: problemas ecológicos e sócio-econômicos. Revista de Estudos Ambientais, Blumenau, v.1, n.1, p. 50-61, jan/abr. 1999.

. Impactos regionais de "grandes projetos" e possibilidades de reorganização do espaço na periferia amazônica In: A DESORDEM ECOLÓGICA NA AMAZÔNIA, 1991, Belém. Conferências... Belém: Unamaz, Ufpa, 1991. p. 253-270. (Série Cooperação Amazônica, n 7).

LEFF, Enrique. Ignacy Sachs y el ecodesarrollo. In: VIEIRA, Paulo Freire et al. (Org.). Desenvolvimento e Meio Ambiente no Brasil: a contribuição de Ignacy Sachs. Porto Alegre: Pallotti, 1998. p.165-172.

MACHADO, Ricardo; AGUIAR, Ludmilla. Desmatamento na Amazônia e consequências sobre a Biodiversidade. In: BRASIL. Ministério do Meio Ambiente (Org.). Causas e dinâmica do desmatamento na Amazônia. Brasília: MMA, 2001. p.225-234

MALDIDIER, Christophe. Le local, le national et l'international dans la gestion des forêts tropicales: une aire protégée au Nicaragua. In: VERDEAUX, François (Ed.). La fôret-monde en question: recomposition du rapport des sociétés à la forêt dans les pays du Sud. Bondy: Editions de l'Aube, Institut de Recherche Pour le Développement, 1999. p.83-96.

NEPSTAD et al. Avança Brasil: os custos ambientais para a Amazônia. Belém: Gráfica e Editora Alves, 2000.

RIBEIRO, Wagner Costa. A ordem ambiental internacional. 1999. 357 p. Tese (Doutorado em Geografia) - USP, São Paulo.

SACHS, Ignacy. Do crescimento econômico ao ecodesenvolvimento. In: VIEIRA, Paulo Freire et al. (Org.). Desenvolvimento e Meio Ambiente no Brasil: a contribuição de Ignacy Sachs. Porto Alegre: Pallotti, 1998. p.161-164.

SANTOS, Milton. A natureza do espaço: técnica e tempo, razão e emoção. São Paulo: Hucitec, 1996.

SMOUTS, Marie-Claude. Forêt tropicales, jungle internationale: le revers d'une écopolitique mondiale. Paris: Presses de Sciences Po, 2001.

THERY, Hervé. Pouvoir et territoire au Brésil: de l'archipel au continent. Paris: Éditions de la Maison des Sciences de l'Homme, 1995.

VIOLA, Eduardo; LEIS, Héctor. Brazil and Global Governance: the case of climate change. In: HOGAN, Daniel; TOLMASQUIM, Mauricio (Orgs.). Humam Dimensions of Global Change, Brazilian perspectives. Rio de Janeiro: Academia Brasileira de Ciências, 2001. 